\title{
As relações familiares do adolescente ofensor sexual
}

\author{
Liana Fortunato Costa - Universidade de Brasilia, Brasilia, Brasil \\ Eikea Lôbo Junqueira - Secretaria de Estado de Saúde do Distrito Federal, Brasilia, Brasil \\ Fernanda Figueiredo Falcomer Meneses - Secretaria de Estado de Saúde do Distrito Federal, Brasilia, Brasil \\ Lucy Mary Cavalcanti Stroher - Secretaria de Estado de Saúde do Distrito Federal, Brasilia, Brasil
}

\begin{abstract}
Resumo
O texto trata de uma pesquisa qualitativa que enfoca o conhecimento das relações familiares do adolescente ofensor sexual, enfatizando as figuras da mãe e do pai, e se baseia nas entrevistas que antecedem o oferecimento de uma intervenção grupal, com os adolescentes e familiares. As entrevistas foram realizadas com sete adolescentes, entre 14 e 17 anos, e suas mães. Foram construídos três núcleos de resultados sobre: a interação familiar desse adolescente se organiza para garantir a sobrevivência da família; esse adolescente apresenta uma intensa e paradoxal relação com sua mãe; e há uma relação extremamente pobre de convivência e vinculação afetiva com a figura paterna. Concluímos que a violência sexual intrafamiliar, cometida pelos adolescentes, está ligada à dinâmica afetiva familiar de distanciamento e autoritarismo. Uma melhor compreensão da violência presente nas relações familiares desse adolescente é fundamental, porque uma característica desses sujeitos é a falta de habilidade social, e esse aspecto provém de um processo pobre de vinculação com seus pais.
\end{abstract}

Palavras-chave: Adolescente ofensor sexual, Família, Violência sexual.

Family relations of the sexual offender adolescent

\begin{abstract}
This text deals with a qualitative research about family relations of the sexual offender adolescent, with emphasis on the paternal figures, and is based on the interviews that precede the offer of a group intervention with the adolescents and their families. The interviews were conducted with seven adolescents and their mothers. Three nuclei results were interpreted: the family interaction of this adolescent is organized to guarantee the survival of the family; this adolescent presents an intense and paradoxical relation with his mother; there is an extremely poor living relation and affective link with the father. We conclude that the intra-family sexual violence made by the adolescents is linked with the family affective dynamics of distance and authoritarianism. A better comprehension of the violence present in the family relations of this adolescent is of fundamental importance because one of their characteristics is the lack of social ability, which originates from a poor process of linking with their parents.

Keywords: Sexual offender adolescent, Family, Sexual violence.
\end{abstract}

Adolescente ofensor sexual y família

\begin{abstract}
Resumen
El texto trata de una investigación cualitativa que enfoca el conocimiento de las relaciones familiares del adolescente ofensor sexual, enfatizando las figuras de la madre y del padre, y se basa en las entrevistas que anteceden el ofrecimiento de una intervención grupal, con los adolescentes y familiares. Las entrevistas fueron realizadas con siete adolescentes, entre 14 y 17 años, y sus madres. Fueron construidos tres núcleos de resultados sobre: la interacción familiar de ese adolescente se organiza para garantizar la supervivencia de la familia; ese adolescente presenta una intensa y paradoxal relación con su madre; y hay una relación extremamente pobre de convivencia y vinculación afectiva con la figura paterna. Concluimos que la violencia sexual intrafamiliar, cometida por los adolescentes, está asociada a la dinámica afectiva familiar de distanciamiento y autoritarismo. Una mejor comprensión de la violencia presente en las relaciones familiares de ese adolescente es fundamental, porque una característica de eses sujetos es la falta de habilidad social, y ese aspecto proviene de un proceso pobre de vinculación con sus padres.
\end{abstract}

Palabras clave: Adolescente ofensor sexual, Familia, Violencia sexual.

Este texto trata de um recorte da pesquisa-ação "Grupos Multifamiliares com adolescentes ofensores sexuais", a qual investiga e sistematiza a proposta metodológica de atendimento a esses sujeitos numa dimensão grupal, reunindo adolescentes e familiares numa abordagem interventiva psicossocial. Essa proposta de pesquisa segue uma tendência atual de conhecer melhor o atendimento familiar como uma coerente indicação de atenção ao adolescente ofensor sexual (Borduin, Schaeffer \& Heiblum, 2009; Henggeler, Melton \& Smith, 1992; Hengeller, Chapman, Borduin, Schewe \& McCart, 2009). Essa pesquisa-ação reúne uma instituição acadêmica e uma instituição pública de atendimento psicológico a adolescentes encaminhados pela Vara da Infância e Juventude (VIJ), para atendimento sob obrigação. Portanto, o texto restringe-se ao recorte já apontado e tem como objetivo o conhecimento sobre as relações familiares do adolescente ofensor sexual, em especial com sua mãe e seu pai, baseando-se nas entrevistas que antecedem ao início do Grupo Multifamiliar (GM), no qual são reunidos os adolescentes, os familiares pertencentes ao núcleo familiar imediato e ao núcleo familiar extenso. 
É preciso reconhecer que não temos, em nosso país, literatura sobre essa temática. Sobre nossa realidade brasileira praticamente não temos números que quantifiquem a incidência de violência sexual praticada por adolescentes. Oliver (2007) chama atenção para que, nem em países mais desenvolvidos, os dados estatísticos refletem a realidade. Esse autor aponta a importância de trabalhos voltados para essa faixa etária, porque esses sujeitos apresentam uma série de sinais, por exemplo, impulsividade, que se tiverem a devida atenção, podem mostrar mudanças efetivas no redirecionamento dessas condutas desviantes. Isso porque, com a concordância de Marshall (2001), esses sinais indicam uma profunda interseção com as interações dos adolescentes com sua família, em especial com pai e mãe.

Constatamos a inexistência de uma estatística apurada sobre o registro de denúncias de abuso sexual contra crianças cometido por adolescentes. Oliver (2007) e Marshall (2001) concordam que 1/3 dos casos de abuso sexual são cometidos por adolescentes. $O$ site da Vara da Infância e da Juventude - VIJ/DF informa dados do CEREVS (Centro de Referência em Violência Sexual) referentes ao ano de 2010 (VIJ, 2010): violência sexual cometida a por irmão - 2,33\%; cometida por primo - 5,81\%; cometida por tio $9,30 \%$. Não encontramos números que indiquem a violência cometida por adolescentes. Esse dado seria fundamental para dimensionar adequadamente $\mathrm{O}$ fenômeno, pois existem estatísticas para tio, irmão e primo. Esses adolescentes ofensores sexuais, participantes da presente pesquisa, abusaram sexualmente de sobrinhos, irmãs ou irmãos e primos/as. Os abusos, caracterizados como "experiências inadequadas" (Forensic Psychology Practice, 2006), tiveram lugar na familia e todos os adolescentes $\mathrm{da}$ pesquisa foram autores dessa modalidade envolvendo irmãos/irmãs, sobrinhos/sobrinhas, primos/primas, isto é, crianças que moravam ou transitavam na casa. Estamos ainda muito distantes de compreendermos como esse fenômeno se configura em nosso país, especialmente com relação às famílias de baixa renda, nossos sujeitos de pesquisa.

\section{$O$ adolescente ofensor sexual e a familia}

Não estamos tratando aqui de pedofilia. Mesmo Seto (2009), especialista neste tema, admite o quanto é difícil realizar um diagnóstico de pedofilia. Esse autor insiste em que pedofilia não é sinônimo de abuso sexual contra crianças. De modo geral, estamos falando sobre adolescentes que, por características ambientais e/ou familiares, incorreram em comportamentos que são violentos contra crianças que ficam sob sua guarda. Muitos autores reconhecem que esses adolescentes não podem ser classificados como portadores de patologia, apesar de terem sido violentos, e enfatizam o papel da família e das circunstâncias sociais na configuração dessas violências (Chagnon, 2008; Forensic psychology practice, 2006; Marshall, 2001; Oliver, 2007). Butler e Seto (2002) fazem uma distinção entre um adolescente que cometeu uma violência unicamente de ordem sexual (sex only) e aquele que cometeu violências de ordem social e sexual (sex plus). Consideramos que nossos adolescentes de pesquisa pertencem à primeira categoria - sex only, desse modo, o contato e a intervenção com a família são essenciais. A segunda categoria, sex plus, reúne aqueles adolescentes usualmente conhecidos em nossa realidade como adolescentes infratores.

Inglaterra, Estados Unidos, Canadá, Austrália e Nova Zelândia são exemplos de países que muito têm se dedicado a estudar e oferecer contribuições teóricas e metodológicas sobre o tema, especialmente na atenção a adolescentes (Madanes, Keim \& Smelser, 1997; Marshall, 2001; Oliver, 2007; Seto, 2009). Em especial, Ward, Gannon e Birgden (2007) são entusiastas de uma abordagem terapêutica a agressores sexuais por encontrarem indícios de respostas muito positivas, principalmente quando se considera a abordagem a adolescentes. Trabalhar com adolescentes ofensores é tratar e prevenir. Atualmente, o reconhecimento da agressão sexual contra crianças é inequívoco, e as publicações têm se dedicado a esclarecer a complexidade do tema e propor avanços metodológicos (Marshall e cols., 2005). A abordagem terapêutica depende de muitos fatores que centram nas habilidades pessoais e técnicas do terapeuta; na abordagem grupal ao adolescente (Marshall e cols., 2005); na consideração da família como parte ativa do processo de ressocialização do jovem (Hengeller e cols., 2009); e na participação de recursos da comunidade (Forensic psychology practice, 2006; Hengeller e cols., 2009; Marshall e cols., 2005; Ward e cols., 2007).

Marshall (2001) aponta que adolescentes abusadores sexuais não necessariamente foram abusados sexualmente, embora esse seja um fator importante no desenvolvimento da conduta agressiva. Mas esse autor compreende que outros aspectos concorrem para o cometimento de atos ofensivos, como: experiências de maltrato físico na infância; ambiente familiar agressivo, contundente e transgressor que propicia um relacionamento destrutivo entre pais e filhos; experiências emocionais que desenvolvem baixa autoestima no adolescente; bem como falta de acolhimento afetivo familiar. Essas características do relacionamento familiar desenvolvem no adolescente, fantasias de dominação e força sobre o outro, como 
forma de enfrentamento de relações sociais e afetivas, e estratégias de "solução" de problemas.

Dos autores consultados (Henggeler e cols., 1992; Marshall, 2001; Marshall e cols., 2005; Oliver, 2007; Timmons-Mitchell, Bender, Kishna \& Mitchell, 2006), é consenso o valor do investimento terapêutico nessa idade para esse problema, tanto no que diz respeito à família como individualmente. Trata-se aqui da ação terapêutica ser vista como prevenção para reincidências dos atos do adolescente ofensor, bem como de mudanças na relação de autoridade da família para com o adolescente. Os autores concordam em sua prática (Marshall e cols., 2005; Ward e cols., 2007) ou em pesquisas (Borduin e cols., 2009; Hengeller e cols, 2009), que intervenções voltadas para adolescentes e suas famílias apresentam enorme potencial de diminuição de novas condutas sexuais agressivas. As intervenções grupais com participação das famílias são vistas como possibilidade concreta e viável. Ainda é providencial apontar que o trabalho com o sistema familiar desse adolescente interfere diretamente nos fatores de risco de reincidência do ato violento, tendo os pais um papel fundamental na interrupção do ciclo repetitivo do abuso sexual (Zankman \& Bonomo, 2004).

Seguindo esta valorização do papel da família, Minuchin (1982), terapeuta de família, trabalha com uma condição inquestionável que é a presença da autoridade dos pais sobre os filhos na reestruturação da organização, dos valores e da lealdade familiar. Para esse autor a estrutura familiar é um conjunto invisível de exigências funcionais que organiza as maneiras pelas quais os membros da família interagem, criando padrões transicionais. A autoridade tem papel organizador fundamental para as relações familiares.

\section{Método}

Trata-se de pesquisa-ação (Barbier, 2002) que associa o oferecimento de proposta de intervenção (as cinco sessões do Grupo Multifamiliar - GM) e preserva a atenção e os rigores aos procedimentos. A pesquisa foi realizada em um ambulatório público de saúde mental, Centro de Orientação Médico Psicopedagógico - COMPP, unidade de Saúde Mental Infanto-juvenil, na cidade de Brasília, que compõe a Rede de Proteção a Crianças e Adolescentes no que diz respeito ao atendimento às vítimas e vitimizadores sexuais. O GM teve duração de agosto a dezembro de 2009, e início com uma entrevista semiestruturada.

\section{Participantes}

Compareceram às entrevistas 7 adolescentes, que participaram do Grupo Multifamiliar, e suas mães. Todos os nomes referidos no texto são fictícios. Segue uma tabela que explicita maiores informações, que foram selecionadas no sentido de contextualizar esse adolescente, situando-o e sua família numa perspectiva socioeconômica.

Tabela 1. Informações sobre os adolescentes

(continua)

\begin{tabular}{|c|c|c|c|c|c|}
\hline & $\begin{array}{c}\text { Escolaridade e inserção } \\
\text { sistema justiça }\end{array}$ & $\begin{array}{c}\text { Família - moradores na } \\
\text { residência }\end{array}$ & $\begin{array}{c}\text { Idade } \\
\text { adolescente }\end{array}$ & $\begin{array}{l}\text { Renda mensal } \\
\text { familiar }\end{array}$ & A vítima \\
\hline Alê & $\begin{array}{l}\text { - } 5^{a} \text { série } \\
\text { - Sem notificação }\end{array}$ & $\begin{array}{l}\text { Mãe (43 anos), padrasto } \\
\text { (34 anos), irmã (16 anos), } \\
\text { adolescente (15 anos), } \\
\text { irmã (10 anos) }\end{array}$ & 15 anos & $\begin{array}{c}830,00 \\
(400,00-\text { mãe }+ \\
\text { 430,00 - benefício } \\
\text { da irmã autista) }\end{array}$ & Irmã (10 anos) \\
\hline Edu & $\begin{array}{l}-2^{\circ} \text { ano do } 2^{\circ} \text { Grau } \\
\text { - Processo na VIJ }\end{array}$ & $\begin{array}{l}\text { Pai (58 anos), mãe (44 } \\
\text { anos), irmã (29 anos), } \\
\text { irmão ( } 28 \text { anos), irmão } \\
\text { (27 anos), irmã ( } 8 \text { anos), } \\
\text { adolescente (17 anos) }\end{array}$ & 17 anos & $\begin{array}{c}1.615,00 \\
(515,00-\text { Edu }+ \\
400,00-\text { mãe }+ \\
700,00-\text { pai })\end{array}$ & $\begin{array}{l}\text { Sobrinha (12 } \\
\text { anos) }\end{array}$ \\
\hline Apê & $\begin{array}{l}\text { - } 8^{\circ} \text { série } \\
\text { - Denúncia feita pelos } \\
\text { pais }\end{array}$ & $\begin{array}{l}\text { Pai (48 anos), mãe (48 } \\
\text { anos), irmã ( } 4 \text { anos), } \\
\text { adolescente (15 anos) }\end{array}$ & 15 anos & $\begin{array}{c}920,00 \\
(420,00-\text { mãe }+ \\
500,00-\text { pai })\end{array}$ & Irmã (4 anos) \\
\hline Wal & $\begin{array}{l}-6^{\circ} \text { série } \\
\text { - Denúncia feita pela } \\
\text { tia }\end{array}$ & $\begin{array}{l}\text { Mãe (51 anos), irmão (27 } \\
\text { anos), adolescente (17 } \\
\text { anos) } \\
\text { Mesmo terreno: Avó ( } 81 \\
\text { anos), avô ( } 77 \text { anos), tia } \\
\text { (43 anos), tia (51 anos), } \\
\text { primo (5 anos) }\end{array}$ & 17 anos & $\begin{array}{c}1.000,00 \\
(200,00-\text { Wal + } \\
800,00-\text { mãe })\end{array}$ & Primo (5 anos) \\
\hline
\end{tabular}

Psico-USF, Bragança Paulista, v. 18, n. 1, p. 33-44, jan./ abril 2013 
Tabela 1. Informações sobre os adolescentes

\begin{tabular}{|c|c|c|c|c|c|}
\hline & $\begin{array}{c}\text { Escolaridade e inserção } \\
\text { sistema justiça }\end{array}$ & $\begin{array}{c}\text { Família - moradores na } \\
\text { residência }\end{array}$ & $\begin{array}{c}\text { Idade } \\
\text { adolescente }\end{array}$ & $\begin{array}{l}\text { Renda mensal } \\
\text { familiar }\end{array}$ & A vítima \\
\hline Jô & $\begin{array}{l}-3^{\circ} \text { ano do } 2^{\circ} \text { Grau } \\
- \text { Caso com notificação }\end{array}$ & $\begin{array}{l}\text { Mãe (35 anos), padrasto } \\
\text { (42 anos), adolescente (17 } \\
\text { anos), irmã (13 anos), } \\
\text { prima ( } 7 \text { anos) }\end{array}$ & 17 anos & 500,00 (mãe) & Irmã (7 anos) \\
\hline Tom & $\begin{array}{l}\text { - } 8^{\circ} \text { série } \\
\text { - Processo na VIJ } \\
\text { - Denúncia feita pela } \\
\text { mãe }\end{array}$ & $\begin{array}{l}\text { Mãe (33 anos), padrasto } \\
\text { (33 anos), meia irmã ( } 7 \\
\text { anos), adolescente (14 } \\
\text { anos) }\end{array}$ & 14 anos & $\begin{array}{c}2.020,00 \\
(1.220,00-\text { mãe }+ \\
800,00-\text { Padrasto })\end{array}$ & $\begin{array}{l}\text { Meia irmã }(7 \\
\text { anos), filha do } 2^{\circ} \\
\text { relacionamento } \\
\text { da mãe }\end{array}$ \\
\hline Go & $\begin{array}{l}\text { - } 6^{\circ} \text { série } \\
\text { - Sem notificação } \\
\text { - Denúncia somente à } \\
\text { instituição, feita pela } \\
\text { mãe }\end{array}$ & $\begin{array}{l}\text { Mãe (34 anos), } \\
\text { adolescente (14 anos), } \\
\text { irmão (10 anos), irmã (11 } \\
\text { anos), irmã (4 anos), irmã } \\
\text { (3 anos) }\end{array}$ & 14 anos & $\begin{array}{c}860,00 \\
(430,00-\text { mãe }+ \\
430,00-\text { auxílio } \\
\text { reclusão })\end{array}$ & Irmã (04 anos) \\
\hline
\end{tabular}

\section{Instrumento}

Antes do início propriamente do GM, todos os adolescentes foram entrevistados para avaliação do comprometimento com a ação praticada e os riscos de reincidência. Essa entrevista contou com os seguintes itens: dados pessoais do adolescente e informações socioeconômicas sobre a família, bem como profissões e/ ou trabalho dos pais, escolaridade dos filhos; descrição do caso de violência sexual intrafamiliar e a posição de cada membro da família perante o fato; organização familiar e construção do genograma; ecomapa; recursos financeiros e sociais da família (renda familiar); situação jurídica do adolescente (se já houve denúncia ou não); informações sobre a vítima tais como idade, grau de parentesco. A família foi convocada para estar presente à entrevista, mas somente a mãe e o adolescente compareceram a essa entrevista. $O$ genograma é um instrumento de avaliação da dinâmica familiar que fornece uma visualização, ao mesmo tempo rápida e profunda, da organização familiar em três gerações, no mínimo (McGoldrick \& Gerson, 1987). O ecomapa é um instrumento que fornece informações sobre a rede social de relacionamentos da família, apontando os recursos de apoio e vinculações sociais que os diferentes membros da família possuem (Sluzki, 1997).

Procedimentos - $\mathrm{O}$ processo de atendimento ao adolescente em contexto familiar (o GM) tem início com uma entrevista que busca reunir as informações que o adolescente e seus familiares têm a oferecer. Como já foi dito, a família, como um todo, é convidada a comparecer. No entanto, somente tivemos acesso, nesse momento, às mães e aos adolescentes. Cada família é entrevistada separadamente; a entrevista tem sua duração em torno de 1 hora, e as perguntas são dirigidas à família como um todo. Após as entrevistas, tem início, então, o GM (Costa, Junqueira, Ribeiro \&
Meneses, 2011), que oferece 5/6 encontros de 3 horas de duração cada um, com intervalo quinzenal. Para o grupo, são convidadas as famílias, os adolescentes, e a rede social de apoio, a família extensa, o grupo de pares do adolescente, padrinhos ou outros que a família eleja durante o processo grupal. Os temas desenvolvidos são: proteção; transgeracionalidade; a dimensão criminal do abuso sexual; os interesses sexuais do adolescente; e o projeto de futuro para o adolescente e a família. A discussão das informações que iremos apresentar baseia-se unicamente naquelas que foram obtidas durante as entrevistas gravadas e depois transcritas. As informações obtidas durante o GM não estão aqui consideradas.

\section{Cuidados éticos}

A pesquisa foi inscrita no Comitê de Ética da Fundação de Ensino e Pesquisa em Ciências da Saúde (FEPECS) da Secretaria de Estado de Saúde do Governo do Distrito Federal (GDF) e aprovada com o parecer $n^{\circ} 331 / 2009$.

\section{Análise das informacôes}

Foi utilizada a análise de conteúdo temática proposta por Deslandes, Gomes e Minayo (2007). A análise foi realizada adotando os seguintes passos: decomposição do material a ser analisado em partes; distribuição das partes em categorias; descrição do resultado da categorização; realização de inferências dos resultados; e interpretação dos resultados obtidos a partir da fundamentação teórica adotada.

\section{Discussão}

Foram construídos três núcleos de interpretação. Vamos apresentar algumas falas que são ilustrativas ao conteúdo interpretado. 
$1^{\circ}$ Núcleo: A familia se organiza para sobreviver - "A gente almoça, toma banho e cama, só dormir mesmo até a hora de ir pro serviço de novo"

Nesse núcleo vamos comentar sobre como a organização familiar se apresenta, como são as relações familiares envolvendo seus vários membros e como a família se organiza para garantir sua sobrevivência. Sobre a organização familiar (Minuchin, 1982), as mães dão testemunho de que "...junta a família inteira e a gente vai conseguindo" (Mãe). Essa fala se refere tanto a juntar os ganhos materiais de seus membros como os do trabalho do marido e da esposa, como a expectativa de que os filhos irão contribuir o mais cedo possível para a renda familiar. O fim de semana é passado na organização e limpeza da casa para enfrentar os dias úteis da semana, que são de muita atividade, garantindo os momentos necessários à continuidade das tarefas domésticas: fazer a comida, arrumar a casa, levar os filhos à escola etc. Todos participam dessa organização de papéis em um rodízio. A questão é que os adultos exercem suas atividades fora de casa e os adolescentes ficam responsáveis pelas tarefas domésticas, tais como: lavar louça, lavar roupa, passar roupa, fazer comida, dar banho nos irmãos menores, arrumar a casa.

No contexto do abuso sexual intrafamiliar cometido por adolescentes em seus irmãos, primos, sobrinhos (crianças que moram ou transitam pela/na casa), pensamos que o papel de "doméstica" que esse adolescente assume é fundamental, ou seja, é preciso atentar para essa condição feminilizante, essa subordinação do adolescente a um papel feminino doméstico. Segato (2010) sustenta que os crimes sexuais apontam ação masculina de subordinação do elemento feminino na intenção de mostrar o quanto o homem pode dominar. Essa interpretação desloca um tanto o ato de abuso sexual da esfera da sexualidade para colocá-lo na esfera da ação motivada por condicionamento de gênero. Os adolescentes da pesquisa mostraram uma condição subordinada às tarefas domésticas durante o dia, executando ações eminentemente femininas. Podemos pensar, a partir do que expõe essa autora, que essa condição feminilizada coloca esse adolescente em uma posição delicada ante condutas masculinas. Esse adolescente não tem muita opção quanto ao serviço doméstico, pois este é o papel esperado pela família.

Além disso, Oliver (2007) fala sobre as fantasias sexuais desses adolescentes e a necessidade de que adultos acolham e orientem sobre essas fantasias. Nos casos observados, encontramos um contexto favorecedor da perpetração da violência sexual: pais fora de casa durante todo o dia e, quando voltam para casa, estão esgotados e querem "Só dormir mesmo"
(Mãe); adolescente alçado à condição de "doméstica" com domínio consentido pelos pais sobre as crianças menores; e um grande investimento de energia e tempo para garantir a subsistência da família (cada um tem que fazer a sua parte). Num contexto de famílias que sobrevivem com 3 ou 4 salários mínimos, temos o que Chagnon (2008) denomina como abuso sexual cometido por adolescentes em decorrência de práticas educativas erradas, como aquelas baseadas em autoritariso e violência. Por outro lado, temos o que Minuchin, Colapinto e Mincuchin (1999) descrevem como características das famílias de baixa renda: a organização familiar se volta inteiramente para a sobrevivência com distribuição de tarefas e responsabilidades, e grande direcionamento das energias para a obtenção de recurso financeiro.

Outra forma que a família busca de organização é o pertencimento e prática de uma religião. "Somos evangélicos e en não achei nada, de forma nenbuma, que ia acontecer isso" (Mãe). O pertencimento a uma religião, sua prática, a ida aos cultos, a presença dos adolescentes nos cultos, parece funcionar como uma prevenção de possíveis descontroles e erros. Percebemos que essa valorização da prática religiosa também funciona como uma prática de união, pois esse valor, para essas famílias, é fundamental (Minuchin, 1982). Parece haver uma confiança de que o ensino religioso, as cobranças e exigências da igreja podem suprir a falta que a presença dos adultos em casa possa representar.

Outro aspecto da forma como a família se organiza constitui-se nas regras de obediência (Minuchin, 1982). É interessante porque esse é o ponto mais enfatizado. As mães estão permanentemente preocupadas com a segurança dos filhos, e temos que reconhecer que têm razão, em função da violência sempre presente nas periferias das cidades grandes. Essas famílias pesquisadas moram em periferias. Para garantir a segurança dos filhos, estes têm que obedecer estritamente às ordens de pai o mãe. Daí este aspecto é primordial: os adolescentes têm que obedecer aos pais, os irmãos menores têm que obedecer aos irmãos mais velhos, os filhos têm que obedecer aos parentes da família extensa, como avós/ôs e tias/os.

Por isso que en tenho que arrumar um empreguinho melhor, só a tarde, tipo de meio periodo [...]. Eu também podia ficar mais em casa, porque eu também fico preocupada. Eu trabalho a noite, mas o coração ta apertado aqui, pensando o que está acontecendo lá em casa? Eu to trabalhando por que to ganhando mesmo, porque enquanto eu não arrumar um trabalbo a tarde não dá. (Mãe)

À noite se eu falar assim: Você não vai, ele não vai, obedece. Obedece a mim, como o pai, se o irmão falar 
também você não vai, ele não vai, se eu falar que não é horário para sair é ponto final. (Mãe)

Ainda com referência a Minuchin (1982) vemos que há uma hierarquia indicando quem obedece a quem. Se por um lado é positiva a presença de uma autoridade, por outro lado, percebe-se que todos mandam no adolescente.

Outra fala aponta que o adolescente tem um papel especial de dar atenção e contenção para a criança que fica com ele em casa: "Aí eu deixava ele com ela ... e ela gostava de ficar com ele" (Mãe). O adolescente é responsável pela ocupação e distração da criança, com a função de babá servindo à mãe, para esta poder trabalhar. A isso se deve acrescer a organização física da casa: "A gente dormia no mesmo quarto" (Adolescente). Faleiros (2008) aponta que é imprescindível reorganizar a casa para restabelecer fronteiras físicas. A prevenção ao abuso sexual intrafamiliar também necessita desse tipo de ação concreta. Minuchin (1982) indica que fronteiras e exercício de papéis compõem a organização familiar. Esse adolescente hora é irmão, hora é pai, hora é mãe. As fronteiras permeáveis, nesse sistema, permitem que o subsistema fraternal seja composto e decomposto cotidiana e rotineiramente. Essa organização familiar voltada prioritariamente para a sobrevivência, sem atentar para as etapas do desenvolvimento de seus membros, é facilitadora da ocorrência do abuso sexual.

As relações familiares revelam ainda que os avós/ôs e tias/os têm papel importante de apoio afetivo. "Ele é o grude da avó dele! [...] é o xodó da avó, desde 87 'quando nasceu! É o neto mais grudado nela ... desde quando eu fiquei grávida, que ele nasceu, ele é o xodó da minha mãe!” (Mãe se referindo ao adolescente) "A tia, ela liga pra ele de vez em quando, e leva ele no parque" (Mãe). Em outro relato o adolescente só pode frequentar lan house com o tio. Essa rede familiar é de suma importância, pois representa o fortalecimento do núcleo familiar para o enfrentamento das crises e situações de conflitos (Marshall, 2001; Minuchin e cols., 1999; Oliver, 2007; Sluzki, 1997).

Autores que se dedicam à temática do adolescente ofensor sexual não abrem mão das intervenções serem planejadas a partir da participação dos membros da família (Borduin e cols., 2009; Forensic Psychology Practice, 2006; Hengeller e cols., 2009; Oliver, 2007; Zankman \& Bonomo, 2004). No contexto dessas famílias pesquisadas, torna-se fundamental a participação de membros, como é o caso da avó e do tio, que se dispõem a apoiar afetiva e concretamente. Hengeller e cols. (2009) denominam essas relações como mediadoras dos impulsos do adolescente e o meio social. Essas relações mediadoras podem estar presentes na família extensa ou na vizinhança ou no grupo de pares. Essa mediação é um contraponto importante às exigências presentes na relação desse adolescente com a mãe, como veremos a seguir.

\section{$2{ }^{\circ}$ Núcleo: A mãe protege e castiga - "Não tenho tempo nem pra mim, vou cuidar de filho?"}

Nesse núcleo vamos apresentar como se dá a intensa e paradoxal relação do adolescente com sua mãe. Em vários estudos sobre o adolescente infrator (Penso \& Sudbrack, 2004; Segond, 1992; Sudbrack, 1992), a figura materna e sua relação com o adolescente tem sido um ponto fundamental na compreensão do ato violento. Essa consideração em relação ao adolescente ofensor sexual não se mostra diferente. A mãe é a referência da família, ela manda, desmanda, controla as atividades domésticas, controla a vida social do adolescente, suas possíveis relações amorosas e o contato com seus pares. E, no entanto, esse adolescente violenta uma regra da casa e agride sexualmente uma criança, desmontando todo o aparato de controle. Por um lado a mãe se desespera com o conhecimento do abuso sexual: "Eu fiquei assim: desorientada. Não sabia o que fazer, quem procurar" (Mãe). Por outro lado, reage fazendo nada: "E aí, eu conversei com meu esposo, que eu acho que foi uma coisa muito séria e pode ser repetida se a gente não tomar uma atitude. Então ... eu falei que ia até numa delegacia, né? Mas eu não fui" (Mãe). Ou mesmo esclarece como se posiciona diante desse adolescente: "Não tenho tempo nem para mim, vou cuidar de filho?" (Mãe).

Chama atenção essa trajetória e paradoxo em relação às reações. Ao mesmo tempo em que desespera, fica paralisada. O impacto emocional é grande, e supomos, por vários outros depoimentos, que o momento é vivido de forma muito solitária: "Porque é dentro da família. Quando é outra pessoa de fora, outra pessoa, você tem a outros pensamentos ... você quer justiça". Parece que o impasse é a dúvida a quem proteger: se denuncia e protege a vítima, a justiça irá condenar o adolescente; se não denuncia e protege $\mathrm{o}$ adolescente, não haverá justiça para a vítima.

Reconhecemos o impasse que paralisa e lembramos Zankman e Bonomo (2004), que apontam os pais como peça significativa na interrupção do ciclo abusivo. A intervenção com os pais, em especial com a mãe, tem que atentar para esse momento de divisão interna em que ela se encontra. Do mesmo modo, a mãe não conta para outros parentes da família extensa, especialmente a avó, quando o adolescente é seu neto preferido. Esse tema de quem proteger merece ter maior atenção e estudo, pois expressa todo o âmago da 
questão da denúncia e da possibilidade de atendimento ao adolescente, à vítima e à família.

Vários são os aspectos que evidenciam uma aliança do adolescente com a mãe. "Aí no sábado, a gente faz faxina. Junta eu e ele e a gente faz faxina. Eu vou lavar as roupas e ele vai arrumando as camas" (Mãe). A mãe conta principalmente com o adolescente para dividir ou delegar as tarefas domésticas.

Ai quando o pai dele chega, aí já tem feito o almoço, aí almoça. Ai vai lavar a casa. E a minha casa, a gente não terminou ela toda, sabe? Ainda tá naquele piso grosso. Uma parte tá rebocada e a outra não. Tem muita poeira, aí a gente lava a casa toda. (Mãe)

A mãe parece poder contar mais efetivamente é com a participação do adolescente, e este acaba, pelo acúmulo de papéis (filho, subordinado doméstico, pai e mãe da irmã), concretizando uma interdependência que ao mesmo tempo protege, mas também pode se mostrar prejudicial.

Um diálogo entre o adolescente e sua mãe mostra a grande interdependência existente entre os dois e o controle que ela exerce sobre o que é direito do adolescente, colocando-se como juiz que julga e promulga a sentença. $O$ diálogo começa com o adolescente Tom reclamando que sua irmã recebe melhor tratamento da mãe do que ele. "Tem diferença?" pergunta a entrevistadora: "Muito!!!" (adolescente chorando). E aí surgem as informações sobre o pai dele:

No dia da morte do pai, ele falou que num queria ir pra escola, eu falei 'não! V ai fica em casa não, vai pra escola, porque fica em casa a toa pensando porcaria!! (Mãe)

No dia da morte do pai ninguém da família falou com ele. (Mãe)

Na época da morte do pai, a tia ainda falou - deixa eu levar ele?! - eu falei não, num levou quando tava vivo! Vai querer levar depois que morreu? Meu filho num vai pra enterro de ninguém não! (Mãe)

Esse evento mostra o quanto a mãe exerce seu poder e impede o filho de ter contato com o pai ainda que morto. Marshall (2001) indica que esses adolescentes provêm de famílias com nível grande de agressividade e conflitos, e que esse adolescente, em particular, sofre violências em nome da boa educação e como princípio norteador da orientação parental.

Zankman e Bonomo (2004) vão apontar que é impossível distinguir o ciclo abusivo do adolescente do ciclo de conflitos dos pais, e isso deve ser tratado como indicação para que a abordagem deva ser familiar. $\mathrm{O}$ controle materno também se estende às possíveis escolhas amorosas do adolescente:

É aquela que você me apresentou lá? ... eu não gostei dela não. Os modos dela, assim o jeito dela. Já aconselhei e falei que ele ta muito novo, agora! Que ás vezes tem muitas mocinhas assim, que dizem ... Vamos ter um filho que é para eu aproveitar. Isso aí acontece muito, mas ele não é filho de papaizinho, ele não é filho de papaizinho, o que a gente tem é suado. (Mãe)

De modo geral, observamos que esses adolescentes ofensores sexuais são alvo de muito controle da família, são cerceados em seu ir e vir, não recebem orientação sexual e a família não acolhe e nem compreende suas fantasias sexuais, tentando mantê-los em casa, seja por meio de proibições, seja por meio de ocupação permanente. Marshall (2001) e Oliver (2007) concordam com essas mesmas observações. Neste ponso reconhecemos que precisamos aprofundar nosso conhecimento sobre as particularidades dessa organização familiar e dessa repressão sexual sobre o adolescente e a violência cometida intrafamiliarmente.

A mãe domina a cena familiar: "E olha que eu faço de tudo pra esses meninos num falta nada! E sabe que tem hora que me dá uma raiva?! Porque eu faço de tudo e ainda reclamam!" (Mãe). A entrevistadora pergunta: Tem espaço para conversar com o filho? Resposta:

De vez em quando, mas é muito raro. Muitas vezes en já to sem paciência de tudo, de escola, de num sei o quê... e eu ando tão cansada que eu num tenho nem ânimo. Ele fala assim: "minha mãe é meia ruim", mas ela é assim pelo meu futuro. Pra no futuro você ser um homem de bem e poder falar que a sua mãe the proporcionou isso! (Mãe)

Vocês conversam? "é porque a vida vai trancando a gente" (Mãe). A dominação tem seu preço e a comunicação, a aproximação afetiva, o cansaço, a sobrecarga de tarefas e obrigações é o preço de ser a figura central.

Em todas as entrevistas somente a mãe compareceu. Tivemos contato com os pais no decorrer da GM. Mas a impressão que permanece é que na relação entre a mãe e o adolescente há pouca interferência do pai ou do padrasto. Essa aliança que hora é protetiva, hora é perversa, segue sendo o mais predominante.

$3^{\circ}$ Núcleo: O pai existe? "O que seu pai fer quando soube do abuso? Conversou"

Nesse núcleo vamos reconhecer uma relação extremamente pobre de convivência e vinculação afetiva com uma figura paterna. A relação mais explícita e dominante é com a mãe. Com o pai, nossas observações ficam restritas. Primeiro, porque a maioria dos adolescentes vive com o padrasto ou companheiro da mãe, e não com o pai biológico. Segundo, porque não fica claro qual vínculo esses homens têm com esses adolescentes. Por um lado não se mostram 
totalmente ausentes das vidas deles. Mas também não se responsabilizam por sua orientação, educação ou exercem autoridade sobre eles. Com relação ao pai biológico, têm pouca ou nenhuma relação concreta.

No item anterior mostramos a interferência da mãe no contato do adolescente com o pai, por ocasião da sua morte. Há outro depoimento de Tom: "Meu pai não me cadastrou! $\mathrm{Na}$ certidão de nascimento. Ele morreu! Eu não sei do meu direito". A mãe interfere e discursa sobre as razões pelas quais o filho não tem o nome do pai:

Tem até um processo judicial, chegou a outra intimação, e eu não vou! Porque ele mesmo disse que não quer ter o nome do pai dele, porque ele nunca teve, e num é agora que eu vou ficar brigando na justiça, depois de morto, pra botar nome do pai dele.

Penso, Costa e Sudbrack (2008), ao estudarem a relação do adolescente infrator com uso abusivo de drogas, compõem um quadro no qual a ausência paterna tem especial significado, porque acaba por existir uma associação afetiva e emocional intensa entre a mãe e o filho. Vemos muita semelhança nessa dinâmica interdependente entre mãe e filho nos casos de uso abusivo de drogas com os casos de abuso sexual intrafamiliar cometido por adolescente com uma irmã/ão, ou prima/o, ou sobrinho/a. Isto porque passa a vigorar um mandato quase impossível de ser desfeito de que essa mãe deve, gradativamente, trazer o filho para uma situação de parentalização com ela. Parentalização é o processo inconsciente que leva um membro da família a assumir um papel desfocado de seu verdadeiro lugar, em relação a outro membro da família (Boszormenyi-Nagy \& Spark, 1983). No caso aqui, vemos um filho elevado a uma posição de marido, dividindo tarefas domésticas como a faxina da casa ou os cuidados com as crianças menores:

Porque ele me traiu! Ele me train com a prima dele primeiro, e ai quando eu descobri eu acabei com a farra dele! [...], ele só voltou pra ir na minha casa quando o Tom tinha nascido... tinha uns três meses. (Mãe)

Zankman e Bonomo (2004) ilustram a importância de que a família seja atendida com a argumentação pautada pela prática. Em nossa experiência verificamos que esses adolescentes encontram-se muito distantes de figuras masculinas importantes, ou protetivas ou presentes em suas vidas. Essas observações estão conectadas a essa realidade socioenonômica? Carecemos de estudos que possam dar prosseguimento a essas observações ainda casuísticas. As entrevistas com os sete adolescentes indicaram, de forma inequívoca, uma lacuna no conhecimento de relação desses adolescentes com seus pais.
E quem fará a interdição? Qual membro da família será a figura simbólica de autoridade que representa o NÃO? A nosso ver não é o pai, mas a mãe. E, nesse sentido, ela representa vários papéis contraditórios que podem, além de estressantes, ser despontecializadores uns dos outros. $\mathrm{Na}$ maioria dos casos estudados, essa mãe se utiliza de violência para o exercício do autoritarismo e não da autoridade. A confusão de exercício simultâneo de papéis e contradições afetivas seguramente coloca esse adolescente em vulnerabilidade. $\mathrm{O}$ adolescente é o filho parentalizado e também o que sofre maiores sanções. É a mãe quem protege, quem castiga, quem denuncia, quem exige, quem interdita e que ainda deveria oferecer carinho e afeição. Percebemos que ao tentarmos elaborar sobre o pai, voltamos a comentar sobre a mãe, em função do papel relevante que possui diante da violência intrafamiliar. Sudbrack (1992) aponta o significado da interdição simbólica, protagonizada pela ação judicial, nessas situações em que o filho comete uma passagem ao ato (violência sexual intrafamiliar) como um pedido de socorro para que seja dada atenção à sua condição de duplo pertencimento a papéis diferentes e complementares. $\mathrm{O}$ acting out (passagem ao ato) ou atuação é definido por Marcelli e Braconnier (1989) como um agir que expressa o conflito, ao invés de um agir, fruto de um processo de reflexão.

Penso, Ramos e Gusmão (2005) indicam uma metáfora construída por adolescentes infratores quando denominam as relações com seus pais: chamam o pai de "pai de botas" (p. 170). Essa metáfora se justifica pela associação entre um pai violento e um policial violento (daí a menção às botas do policial), que não apresentam diferenças na forma como lidam com esse adolescente. Nossos sete adolescentes da pesquisa relataram episódios de violência contra eles, surras e o uso de pancadas como forma de educar, orientar e disciplinar. Esses episódios, como nos foi permitido perceber, estão mais conectados à ação da mãe. Com esses adolescentes ofensores sexuais, temos uma mãe de botas?

Achamos pertinente, ao finalizar, retomarmos o quadro de informações sobre os adolescentes, porque além das informações contidas, os dados também nos apontam questões que ainda necessitam de respostas. Um aspecto chama atenção e merece uma investigação mais específica: todos os adolescentes se encontram em escolaridade relativamente compatível com sua idade, não se vendo grandes defasagens ou abandono da escola. Uma pesquisa do Ministério Público do Distrito Federal e Territórios (2010) aponta que 55\% dos adolescentes infratores estão no ensino fundamental. Outro aspecto diz respeito aos sete adolescentes, 3 
residem com o padrasto, 2 com o pai biológico e 2 não possuem uma figura masculina de adulto em casa. Essa mesma pesquisa também aponta que $82 \%$ têm a mãe na residência e $38 \%$ têm o pai na residência. Essas observações relativas ao nosso pequeno universo de 7 adolescentes e a pesquisa acima citada, que envolveu 504 adolescentes infratores, indica que há ainda muito o que desvendar e melhor compreender quanto a particularidades do adolescente ofensor sexual em relação ao adolescente infrator de modo geral, que é um sujeito um pouco mais conhecido até o momento.

\section{Considerações finais}

A literatura disponível trata, de forma geral, o interesse pela família do adolescente ofensor sexual em textos que têm um tratamento quantitativo por meio de pesquisas com teor mais avaliativo do que compreensivo. Apontamos uma ausência de literatura nacional sobre esse tema. Por enquanto, temos que nos pautar em textos em sua maioria de língua inglesa, que retratam uma realidade socioeconômica muito diferente das famílias com quem temos contato. O limite deste texto mostra-se na dificuldade de estabelecermos relações com conhecimento já conhecido de nossa realidade.

Consideramos que conseguimos compor um quadro dinâmico das relações desse adolescente com a mãe e o pai, maior objetivo do texto. A mãe desse adolescente ocupa papel fundamental na dominação e autoritarismo com que o trata. O pai, por sua vez, encontra-se distante ou ausente, não conseguindo equilibrar as relações estressantes entre a mãe e o filho.

Uma melhor compreensão da violência presente nas relações familiares desse adolescente é fundamental. Além de corroborar a necessidade de que o atendimento seja em uma abordagem familiar, autores como Seto (2008) chamam atenção para uma característica desses adolescentes que é um processo pobre de vinculação com seus pais, como ficou explícito na análise da relação com a mãe e o pai. Percebemos que, para o adolescente ofensor sexual que cometeu violência intrafamiliar, que permanece com os vínculos familiares preservados, reside com os pais, estuda em série razoavelmente compatível com sua idade (esses são indicadores que conseguimos reunir), a intervenção com a família é fundamental, porque compreendemos que a violência perpetrada está intimamente ligada com a qualidade das relações com os membros da família. Reconhecemos que ainda temos muito a descobrir dos efeitos paradoxais sobre o cuidado e a violência que coexistem nessas relações.

Conhecemos pouco esse adolescente ofensor sexual em termos individuais e esse texto o enfoca na relação com sua família, que foi, no momento, nossa opção de intervenção. É preciso que estudos sobre as características individuais sejam realizados.

\section{Referências}

Barbier, R. (2002). A pesquisa-ação (L. Didio, Trad.). Brasília, DF: Plano.

Borduin, C. M., Schaeffer, C. M. \& Heiblum, N. (2009). A Randomized Clinical Trial of Multisystemic Therapy with juvenile sexual offenders: effects on youth social ecology and criminal activity. Journal of Counseling and Clinical Psychology, 77(1), 26-37.

Boszormenyi-Nagy, I. \& Spark, G. M. (1983). Lealtades invisibles, Buenos Aires: Amorrortu.

Butler, S. M. \& Seto, M. (2002). Distinguishing two types of adolescent sex offenders. American Academy of Child Psychiatry, 41(1), 83-90.

Chagnon, J-Y. (2008). As agressões sexuais: uma organização de transtornos narcísico-identitários. Paidéia, 18(41), 495-515.

Costa, L. F., Junqueira, E. L., Ribeiro, A. \& Meneses, F. F. F. (2011). "Ministério da Obrigação adverte": é preciso proteger os adolescentes ofensores sexuais. Avances em Psicologia Latinoamericana, 29(1), 33-46.

Deslandes, S. F., Gomes, R \& Minayo, M. C. S. (Orgs.) (2007). Pesquisa social: teoria, método e criatividade $\left(25^{\mathrm{a}}\right.$ ed. revista e atualizada). Petrópolis, RJ: Vozes.

Faleiros, V. (2008). Parar o abuso e desenvolver a proteção. Em L. F. Cost \& H. G. D de Lima (Orgs.). Abuso sexual. A justiça interrompe a violência (pp. 159-170). Brasília, DF: Liber.

Forensic Psychology Practice (2006). Adolescent sex offenders. A practitioner's portfolio. Boldmere: The Willow Clinic.

Henggeler, S. W., Melton, G. B. \& Smith, L. A. (1992). Family preservation using multisystemic therapy: an effective alternative to incarcering serious juvenile offenders. Journal of Consulting and Clinical Psychology, 60(6), 953-961.

Hengeller, S. W, Chapman, J. E., Borduin, C. M., Schewe, P. A. \& McCart, M. R. (2009). Mediators of change for multisystemic therapy with juvenile sexual offenders. Journal of Counseling and Clinical Psychology, 77(3), 451-462.

Madanes, C., Keim, J. P. \& Smelser, D. (1997). Violencia Masculina. Barcelona: Granica.

McGoldrick, M. \& Gerson, R. (1987). Genetogramas en la evaluación familiar. Buenos Aires: Gedisa.

Marcelli, D. \& Braconnier, A. (1989). Manual de psicopatologia do adolescente (A. E. Filman, Trad.). 
Porto Alegre, RS: Artes Médicas. (Original publicado em 1984).

Marshall, W. L. (2001). Agresores sexuales. Barcelona: Ariel.

Marshall, W. L., Ward, T., Mann, R. E., Moulden, H., Fernandéz, Y. M., Serran, G. \& Marshall, L. E. (2005). Working positively with sexual offenders: maximizing the effectiveness of treatment. Journal of Interpersonal Violence, 20, 1096-1114.

Ministério Público do Distrito Federal e Territórios (2010). Relatório de pesquisa. Perfil do adolescente infrator. Brasilia: Secretaria de Planejamento SECPLAN.

Minuchin, S. (1982). Famílias. Funcionamento \& tratamento (J. A. Cunha, Trad.). Porto Alegre, RS: Artes Médicas. (Original publicado em 1980).

Minuchin, P., Colapinto, J. \& Minuchin, S. (1999). Trabalhando com Famílias Pobres (M. F. Lopes, Trad.). Porto Alegre, RS: Artes Médicas (Original publicado em 1998).

Oliver, B. E. (2007). Three steps to reducing child molestation by adolescents. Child Abuse \& Neglect, 31, 683-689.

Penso, M. A. \& Sudbrack, M. F. O. (2004). Envolvimento em atos infracionais e com drogas como possibilidade para lidar com o papel do filho parental. Psicologia USP, 15(3) 29-54.

Penso, M. A., Costa, L. F. \& Sudbrack, M. F. O. (2008). A transmissão geracional no estudo da relação adolescente, droga e ato infracional. Em M. A. Penso \& L. F. Costa (Orgs.). A transmissão geracional em diferentes contextos (pp. 143-164). São Paulo, SP: Summus.

Penso, M. A., Ramos, M. E. C. \& Gusmão, M. M. (2005). O pai de botas. Em L. F. Costa \& T. M. C. de Almeida (Orgs.). Violência no cotidiano. Do risco à proteção (pp. 167-183). Brasília, DF: Liber Livros / Universa.
Segato, R. L. (2010). Crimes de gênero em tempos de "paz" e de guerra. Em C. Stevens, K. C. T. Brasil, T. M. C. Almeida \& V. Zanello (Orgs.). Gênero e feminismos: convergências (in)disciplinares (pp. 49-62). Brasília, DF: Ex Libris.

Segond, P. (1992). Familia e transgressão. Psicologia: Teoria e Pesquisa, 8(suplemento), 433-445.

Seto, M. (2008). Pedophilia and sexual offending children. Theory, assessment and intervenction. Washington, DC: American Psychology Association.

Seto, M. (2009). Pedophilia. Annual Review of Clinical Psychology, 5, 391-407.

Sluzki, C. E. (1997). A rede social na prática sistêmica. (C. Berliner, Trad.). São Paulo, SP: Casa do Psicólogo. (Original publicado em 1997).

Sudbrack, M. F. O. (1992). Da falta do pai à busca da lei: o significado da passagem ao ato delinqüente no contexto familiar e institucional. Psicologia: Teoria e Pesquisa, 8(suplemento), 447-457.

Timmons-Mitchell, J., Bender, M. B., Kishna, M. \& Mitchell, C. C. (2006). An independent effectiveness trial of multisystemic therapy with juvenile justice youth. Journal of Clinical Child and Adolescent Psychology, 35(2), 227-236.

VIJ (Vara da Infância e da Juventude) (2010). Dados consolidados 2010. Disponível em: http://www.tjdft.jus.br/trib/vij/docVij/estatis/20 10/vij_estatisticaViolSex.pdf. Acesso em: 5/5/2010, 2010.

Ward, T., Gannon, T. A. \& Birgden, A. (2007). Human rights and the treatment of sex offenders. Sex Abuse, 19, 195-216.

Zankman, S. \& Bonomo, J. (2004). Working with Parents to reduce juvenile sex offender recidivism. Journal of Child Sexual Abuse, 13(3/4), 139-156.

Recebido em: 22/06/2011

Reformulado em: 05/03/2013

Aprovado em: 06/03/2013 
Sobre as autoras:

Liana Fortunato Costa é psicóloga, terapeuta conjugal e familiar, psicodramatista e doutora em Psicologia Clínica pela Universidade de São Paulo no Programa de Pós-Graduação em Psicologia Clínica e Cultura PSICC/PCL/IP/UnB.

Eika Lôbo Junqueira é psicóloga, psicopedagoga e especialista em Análise do Comportamento. Trabalha no Centro de Orientação Médico Psico-pedagógico - COMPP - Secretaria de Estado de Saúde do Distrito Federal.

Fernanda Figueiredo Falcomer Meneses é psicóloga. Trabalha no Centro de Orientação Médico Psicopedagógico - COMPP - Secretaria de Estado de Saúde do Distrito Federal.

Lucy Mary Cavalcanti Stroher é assistente social e terapeuta familiar. Trabalha no Centro de Orientação Médico Psicopedagógico - COMPP - Secretaria de Estado de Saúde do Distrito Federal.

Contato com as autoras:

SQN, 104 - Bloco D - apartamento 307 - CEP 70733-040 - Brasília/DF, Brasil.

E-mail: lianaf@terra.com.br 
